\title{
Application of New Concept for Multiple Intelligences Calculation for Personality and Social Groups Comparison Research
}

\author{
Viktor Minkin, Yana Nikolaenko \\ Elsys Corp., St. Petersburg, Russia \\ Email:minkin@elsys.ru
}

How to cite this paper: Minkin, V. and Nikolaenko, Y. (2017) Application of New Concept for Multiple Intelligences Calculation for Personality and Social Groups Comparison Research. Journal of Behavioral and Brain Science, 7, 447-463. https://doi.org/10.4236/jbbs.2017.710032

Received: July 6, 2017

Accepted: October 8, 2017

Published: October 12, 2017

Copyright (c) 2017 by authors and Scientific Research Publishing Inc. This work is licensed under the Creative Commons Attribution International License (CC BY 4.0). http://creativecommons.org/licenses/by/4.0/

\begin{abstract}
A person is considered as information-energy system with a host of feedbacks. The possibility of determining the statistical characteristics in a multiple intelligences profile of various social groups' representatives using the vibraimage technology is investigated. Theft and alcohol abuse have been chosen as examples of significant social problems including deviant behavior and the trigger of formation of various socially vulnerable groups. The comparative analysis of conscious and unconscious attitudes in multiple intelligences structure of individuals prone to deviant behavior and the control group allows differentiating professional preferences and the impact of society on different social groups.
\end{abstract}

\section{Keywords}

Vibraimage Technology, Multiple Intelligences, Alcohol Abuse,

Theft, Psychophysiology, Social Groups

\section{Introduction}

One of the central problems in psychology and psychophysiology, both in theoretical and practical aspects, is the array of questions related to behavior and intellectual activity of a person. Almost any kind of human activity can be seen as behavioral act or a consequence of mental organization. This statement allows us to use and analyze multiple intelligences, the concept introduced by Howard Gardner [1] [2], at the intersection of behavioral, psychological, physiological and social activity. The research of behavioral statistical features of various social groups becomes especially urgent recently with a stable tendency of social networks increasing influence in the modern society. It is known that one of the 
most informative areas characterizing personality and behavior of a person is physiology of activity. The founder of Russian physiology, Ivan Sechenov, argued that each thought has its muscular manifestation [3]. Great Charles Darwin on the basis of the theory of evolution in the book The Expression of the Emotions in Man and Animals [4] assumed that "reflex actions characterize the expression of emotions". The founder of psychoanalysis Sigmund Freud considered that "a person has no random movements" [5]. The first Russian Nobel prizewinner Ivan Pavlov, the most famous in the world researcher of reflexes, claimed that all physiological phenomena are determined by two processes of excitation and inhibition [6]. The famous Russian psychophysiologist Nikolai Bernstein who introduced into science the term "activity physiology" found that any movement of a person is discrete and based on biofeedback [7]. A prominent biologist and psychologist of the 20th century, Nobel laureate Konrad Lorenz in his book Aggression (1966) declared that the one who will manage to measure the amplitude and intensity of reflex movements will be able to determine the level of aggression [8]. Brazilian psychologist Emilio Mira y López [9] offered a practical technique of the personality parameters analysis on repeatability of movements (myokinetic diagnostics) as early as in the sixties of the last century. The principles of physiology of activity developed by great scientists formed the basis of modern vibraimage technology [10], which converts the data of reflex head micromovements to psychophysiological characteristics of a person.

\section{Multiple Intelligences and Deviant Behavior}

It is known that there are several different approaches to the analysis of human intelligence. Initially it was assumed that any intellectual activity contains a single common factor called by Spearman C. E. [11] and his followers-the "general" (g). In other words, intelligence was seen as an indivisible whole ("g") [12] [13]. Howard Gardner is an opponent of the theories of indivisible intelligence and test approach to abilities diagnostics, reflecting, in his opinion, the level of awareness positioned within a particular subculture [14]. They contain "proficiency/awareness" coefficient but not abilities parameters.

At the same time, it is the concept of "multiple intelligences" that allows exploring the relationships between abilities and the ways of their realization in various areas of activities.

Traditionally, theft and alcohol abuse are regarded as the most known forms of deviant behavior.

Psychological approach to a comprehension of deviant behavior relates its origin to intrapersonal conflict, destruction and personality self-destruction. In fact, the essence of deviant behavior should be considered as blocking personal growth and even personal degradation that is a consequence, and sometimes the purpose of deviant behavior. Rallying a group of carriers of different forms of deviant behavior leads to the mutual reinforcement of antisocial tendencies and 
is a serious social problem [15] [16]. The mechanisms of sustained illegal actions formation (systematic theft, for instance) are slightly different from regular alcohol abuse. At the same time, the rallying of carriers similar in the forms of deviant behavior allows to monitor group-wide trends, the focus of intellectual and social activity.

The search of sustained biometric characteristics of deviant behavior is a longstanding dream for criminalists, the most famous of whom was an Italian psychiatrist Cesare Lombroso [17], whose main idea was that of a born criminal. It is known that biometric technologies [18] according to their defined characteristics are divided into biological (static) and behavioral (dynamic). Lambrozo's researches, certainly, relate to the identification of biological signs of deviant behavior. Currently, also the majority of researches are aimed at finding the biological characteristics that define personality including his/her intelligence [19] [20]. Despite this, we assume that behavioral dynamic characteristics of a person, such as multiple intelligences (MI) and vibraimage parameters are more informative characteristics of personality than biological and static indications

\section{Vibraimage Technology and Multiple Intelligences}

The vibraimage technology [10] is a biometric technology that allows obtaining the information on a psychophysiological state of a person via software processing of the person's video image. A vibraimage is obtained when realtime converting a luminous video image of an object into the vibraimage formed by the accumulated frame-to-frame difference [21] [22]. This approach allows obtaining information only on moving objects and enhancing the signals of the objects making vibrations. The head of a person in a quasi-stationary state constantly makes slight micromovements and movements (vibrations), and the parameters of these micromovements depend on a psycho-emotional and psychophysiological state of a person and are conditioned by the vestibular-emotional reflex [23]. There is quite a large number of modern scientific works associating brain activity, including intelligence level, with topological features of brain development [19] [24] [25]. However, a static topological binding of abilities to certain areas of the brain contradicts the constant development and change of human perception. To reflect dynamic processes that are constantly occurring in a human body it is necessary to apply the black box principle proposed by the founders of cybernetics [26] [27]. The methodological basis of a research involves establishing a clear principle for intelligence profile structuring as an integral phenomenon. The lack of this principle makes the concept of intelligence profile no more than an arbitrary set of factors (the list) that affect a person's life.

Thus, there are three main problems in Gardner's MI structure:

1) the lack of the leading principle for intelligence profile structuring as an integral phenomenon;

2) the uncertainty of the scientific approach that objectively reflects the principle of structuring; 
3) an unfinished structuring and specification of a complete list of multiple intelligences.

Attempting to resolve the designated problems, we applied the dichotomy principle within the evolutionary approach as a logical division of a class into subclasses where the divisible concept is completely divided into two mutually exclusive ones. One and the same person cannot be at the same time a distinctively expressed extrovert and introvert, as well as an expressed intrapersonal intelligence cannot go with distinctively expressed interpersonal intelligence. Each type of intelligences should have an oppositional type, counter on a certain psychophysiological feature. In the history of psychology and biology the principle of dichotomy is common. At the same time, from physical perspective, classification of such phenomena can be limited to one scale, for instance, of extroversion (for introvert-extrovert classification). It is appropriate to take into account the approach developed in psychology also in the proposed classification of multiple intelligences. In addition, proceeding from the Darwinian approach to the evolution of species, the intelligence structure of a person must be inextricably intertwined with the current distribution of specialties relevant to this historical period.

From modern neurophysiology perspective, the intelligence profile in many respects is determined by the development of connections between neurons of the brain; this process is constantly going on in the head of every man due to age-related changes and phenological effects [28] [29]. Proceeding from the specified assumptions, the list of the available multiple intelligences according to Gardner needs to be expanded since the "existential-theoretical" intelligence appeared to be "without pair", and in the classification given by Gardner there are no intelligence characteristics associated with the attitude to wealth accumulation and business (modern component of a successful person, a refraction of his/her abilities). We have added to a new classification of multiple intelligences three types of intelligences: business-mercenary, its counterpart-ascetic-sacrificial, and arts-bohemian complementing existential-theoretical intelligence (Figure 1).

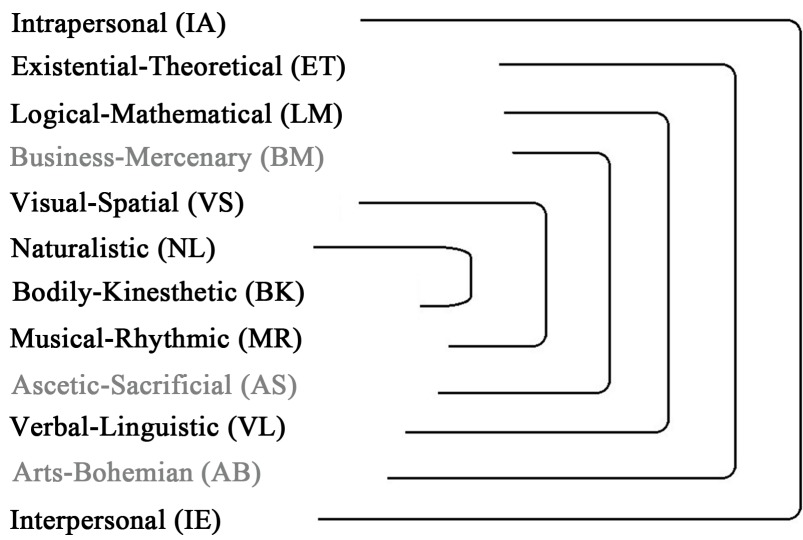

Figure 1. Extended and expanded Gardner's classification of multiple intelligences. 


\section{Research Study Aims and Objectives}

The aim of this research is to determine and investigate the relationships between a standard profile of multiple intelligences, its differential conscious-unconscious component and the specificity of behavior of social groups, for example, predisposition toward behavioral disorder. The research was conducted with the help of the VibraMI program, developed by the company Elsys Corp., St. Petersburg, Russia [30] [31], which analyzes the motor activity of a person together with his conscious response to stimuli. Achieving this purpose involves the following tasks to be solved: the analysis of the general (integral) profile of multiple intelligences and the comparison of the results obtained with the predominant type of social activity; the analysis of conscious and unconscious attitudes as structural MI components; the analysis of the difference (differential MI profile) between conscious and unconscious structural components of the MI profile.

\section{Theoretical Background}

The measurement or assessment of mood, character, abilities or any other psychophysiological characteristics of human personality should be considered a measurement related to the areas of biometrics and psychophysiology. Despite the fact that biometrics and psychophysiology are fairly modern terms, the assessment of human personality properties has been carried out since the beginning of the existence of mankind. Thus, the need to create a diagnostic tool that is accessible and comfortable in use both for an expert and for any person interested in objective definition of their abilities and solving the problem of career choice at any stage of their life, is long overdue. In the course of the experiments it was found that going through a questionnaire containing 24 issues is optimal and does not cause mental exhaustion of examinees [30]. VibraMI [31] program applied for testing multiple intelligences profile, allows to obtain an integral (summarized) MI profile, using the given values of conscious and unconscious responds when answering questions during presentation of visual stimuli, and a differential (subtractive) profile of conscious and unconscious responds.

A conscious response of an examinee is determined when processing the answers to the questions presented in the "Yes/No" format. The content-related aspect of the questionnaire incorporated in the VibraMI program meets the main criteria of the questionnaires of interests and attitudes on the one hand, and the abilities test, on the other hand. The content of the questions is directly related to potential interests of a respondent, and their formulation allows estimating the orientation of attitudes. The direction of change in a psychophysiological state of an examinee can be detected by tracing the change in psychophysiological response to the question in the scales of information and energy [30] [31] reflecting the corresponding alteration in the person's information and energy state.

The informational component of a psychophysiological response represents an alteration in informational exchange between and in physiological systems of 
a person when exposed to a stimulus. An internal informational state of a person can be estimated as informational efficiency coefficient $I_{\text {in }}$ which reflects the ratio of useful volume of received physiological information to the total amount of the transmitted physiological information.

The developers of the vibraimage technology argue that such informational efficiency coefficient [32] is proportional to the function of the sum of correlations of the work of various physiological systems $\left[I_{i n}=f\left(\sum_{1}^{k n}\left(C_{k n}\right)\right)\right]$, and this process can be estimated in various technical ways, e.g., by means of the vibraimage technology or when measuring the total correlation of temporal dependences of various physiological signals. The decrease in correlation dependence between the functioning of the various human physiological systems is characterized by loss of control, chaos, entropy increase. Analogic technical approach to a person has been previously used by others psychophysiological researches. For example, LibbThims in his work Human Chemistry argued that all the questions of consciousness and unconsciousness can be reduced to chemical processes [33]. Similar behavioral approach to the study of human personality was used by the founder of the method of functional analysis in behaviorism, Skinner Burrhus Frederic [34], who did much to transfer psychological theories to the practical area. An important contribution to the development of technical approach in the study of activity physiology was made by the prominent Russian psychophysiologist Nikolai Bernstein [7].

\section{Methods}

\subsection{Participants}

Testing of MI participants in the experiment using vibra imaging technology was carried out in the first half of 2017. In the course of the organized experiment, we examined 60 people from whom three groups were created. Twenty (20) students of the Institute specializing in jurisprudence at the age of $20-28$ years, 11 females and 9 males were surveyed as control group. The first experimental subgroup included 20 young men and girls, regular alcohol drinkers, and 20 young men and girls who systematically committed petty theft (thieves) were combined in the second experimental subgroup. The age range of the experimental group participants made from 19 to 27 years, 28 male people and 12 female people. $85 \%$ of the participants were white Russian, 15\% were Caucasian. The permission from the colleges was obtained to ensure that the study conforms to the ethical standards. Further, all participants of the experimental group were subdivided into two subgroups, according to the direction of deviant behavior-alcohol abuse or the systematic theft (20 people per group). The division of examinees according to sexual, family or other criteria was not carried out.

\subsection{Procedure}

Practical testing of multiple intelligences in examinees by means of the vibrai- 
mage technology by the VibraMI program was carried out as follows: an examinee sits in front of the computer, sees on the monitor screen sequentially emerging questions and images, answers the questions in the Yes/No format pushing the specified buttons in the software interface. At the same time, the monitor is equipped by the Microsoft LifeCam Cinema web camera which transmits the video image of an examinee to process it by the VibraMI program. The program converts the video to a vibraimage, and processes it synchronously with the obtained conscious answers to the questions according to the algorithm specified by the developers [31]. The testing lasts five minutes, and after the examinee has answered the 24 presented questions, the program builds the integral profile of multiple intelligences of the examinee, based on the obtained conscious and psychophysiological (unconscious) response (reactions), and the MI differential profile. The resultant individual file of each examinee is created in the Excel format, and after testing of a group it is subjected to statistical processing by means of the VibraStat3 [32] program. The VibraStat3 program automatically averages the values for each MI type in the group, and creates the file of average values of the MI types for the processed group. Certainly, similar statistical processing of individual files of the MI profile can be carried out manually, for example, by means of Excel.

\section{Result: General MI Profile Analysis}

Viewing one's own abilities is a process that includes both conscious perceptions and covert, unconscious attitudes [5]. It is difficult to overestimate the importance of conscious attitudes in a person's life, as they are closely intertwined with conative processes and achievement motivation. Unconscious attitudes are traditionally associated with the sphere of fears, personal insecurity, etc. Both of these poles, conscious and unconscious, in combination, reflect the self-esteem of human abilities, perceptions of their own intelligence (multiple intelligences), determine the direction of social activity.

Figure 2 shows the distribution of the MI profiles obtained during the experiment described for all 3 specified groups.

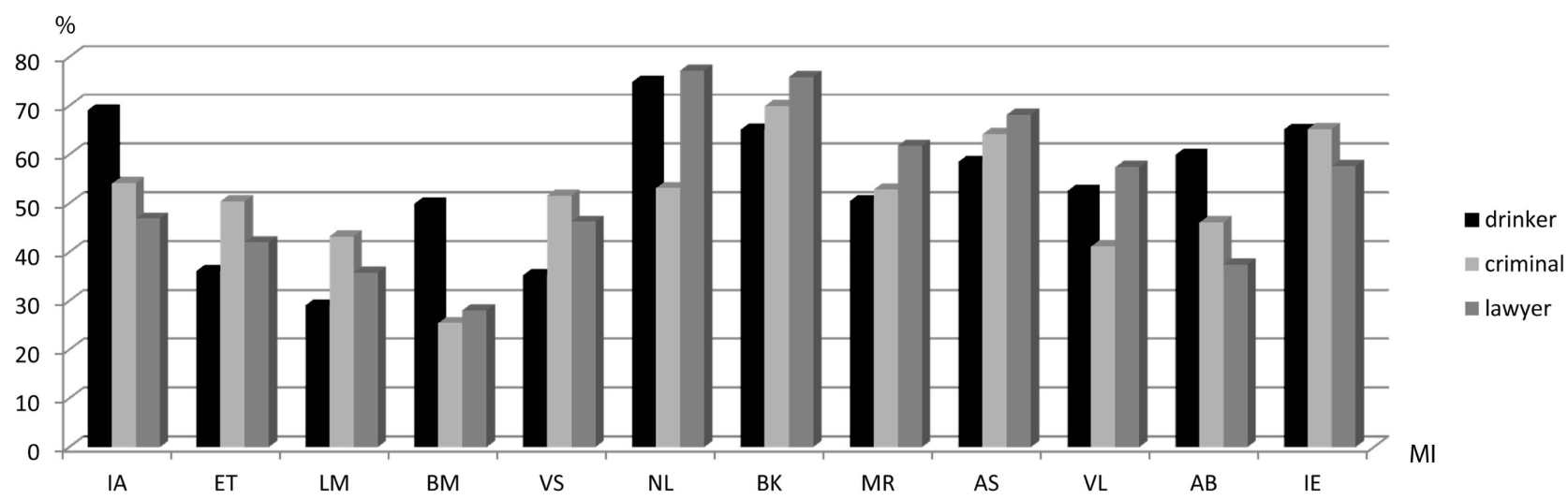

Figure 2. Integral multiple intelligences profile. 
Figure legend for MI types: IA-Intrapersonal; ET-Existential-Theoretical; LM-Logical-Mathematical; BM-Business-Mercenary; VS-Visual-Spatial; NL-Naturalistic; BK-Bodily-Kinesthetic; MR-Musical-Rhythmic; ASAscetic-Sacrificial; VL-Verbal-Linguistic; AB-Arts-Bohemian; IE-Interpersonal.

Let us consider the three leading MI types defining the general direction of social activity and professional preferences in the representatives of different groups. It turned out that in the group of young people who abuse alcohol the MI types are NL-naturalistic (74.8\%), IA-intrapersonal (69\%) and IE-interpersonal (65\%). In general, the examinees of this group perceive themselves as misunderstood by society, striving to seclusion (IA MI) more than to collective interaction.

In the group of young people who systematically committed petty theft the leading MI types appeared to be BK-bodily-kinesthetic (69.9\%), IE-interpersonal $(65.2 \%)$ and AS-ascetic-sacrificial (64\%). It is possible to say that the orientation of social activity of the young people who systematically committed petty theft is determined by the need for intensive group and motor interaction, and the distorted ideas of justice (AS MI).

In the control group of students studying jurisprudence the leading MI types became NL-naturalistic (77\%), BK-bodily-kinesthetic (75.9\%) and AS-ascetic-sacrificial (68.1\%), the leading pairs being NL/BK, AS/BM.

The maximal distinctions between the groups of examinees are concerning business-mercenary $(\mathrm{BM})$, naturalistic $(\mathrm{NL})$ and arts-bohemian $(\mathrm{AB})$ types of MI. The persons prone to alcohol addiction consider themselves ready to do business to a greater extent than the persons who committed theft ( $\Delta 24.4 \%)$ and law students $(\Delta 21.8 \%)$. The persons who committed theft are indifferent to nature unlike the persons with alcohol addiction $(\Delta 21.8 \%)$ and law students $(\Delta$ $24 \%)$. Demonstrative behavior in the individuals with alcohol addiction is more expressed, than in law students $(\Delta 22.5 \%)$ and young people who committed theft $(\Delta 13.9 \%)$. The interpretation of the data obtained closely intertwines with the diversity of social factors of professional self-fulfillment. Internal readiness to do business given low resistance to competitive struggle, low communicative flexibility and defects of education indulge the development of alcohol addiction, various depressive and neurotic syndromes. The heavier an internal struggle proceeds, the brighter is the ostentation being a psychological defense against a nerve strain. Therefore these abilities are expressed so poorly in law students and the persons who committed theft.

In order not to clutter Figure 2 with additional data we did not give there the value of root-mean-square deviation (RMSD) on the MI types in groups. We only note that for the leading MI types the minimum RMSD value was obtained in the group of alcoholics (16.4\%) for naturalistic intelligence (75\%), and the maximum RMSD value (26\%) was obtained in the group of thieves for bodily-kinesthetic intelligence (70\%) which indicates a greater intellectual cohesion in the group of alcoholics under study compared with a group of thieves. 
The obtained results of human variability in social groups are given in the form of mathematical statistics (Table 1). Table 1 presents data on mathematical expectation (M) and standard deviation $(\sigma)$ for each type of MI, in all the surveyed groups, for the general (integrated profile) MI. Table 1 results for $\mathrm{M}$ are the same as presented on Figure 2, MI theory supposed that people with leading VS MI type prefer graphs, but the people with leading ML type of MI prefer tables for data analysis. So we double $\mathrm{M}$ results in Figure 2 and Table 1 for readers with the different types of leading MI.

Human variability (indicated by SD of $M$ value in groups) is one of the most interesting parameters in a human study [35] and could have civil and military applications. Based on given results the standard deviation for different MI types in one social group (for example drinkers) could have 2 times difference (minimum $16 \%$ for NL and maximum $32.5 \%$ for MR). M value typical standard deviation about $20 \%-30 \%$ based our opinion is normal result for any

\subsection{Analysis of Conscious and Unconscious Components of MI Profile}

The MI profile represented in Figure 3 illustrates conscious perception of the examinees about their intellectual capacities and needs, i.e. a desirable or idealized MI profile, from the view point of self-esteem. The results reflect a traditional psychological test approach to diagnostics of any new mental formations on the basis of self-esteem of the examinees.

Table 1. Mathematical expectation and standard deviation (SD) for each type of MI (to Integral multiple intelligences profile).

\begin{tabular}{cccccccccccccc}
\hline \multirow{2}{*}{ MI } & \multirow{2}{*}{ Groups } & IA & ET & LM & BM & VS & NL & BK & MR & AS & VL & AB & IE \\
\cline { 3 - 13 } & & $\%$ & $\%$ & $\%$ & $\%$ & $\%$ & $\%$ & $\%$ & $\%$ & $\%$ & $\%$ & $\%$ & $\%$ \\
\hline \multirow{2}{*}{ Drinker } & $\mathrm{M}$ & 69.1 & 36.1 & 29 & 49.9 & 35.2 & 74.8 & 65.1 & 50.4 & 58.5 & 52.5 & 59.9 & 65.1 \\
& $\sigma$ & 32.1 & 25.1 & 29.5 & 30.4 & 29.5 & 16.4 & 23.9 & 32.5 & 29.2 & 27.9 & 27.9 & 25.2 \\
Criminal & $\mathrm{M}$ & 54.1 & 50.4 & 43.2 & 25.5 & 51.6 & 53.1 & 69.9 & 52.8 & 64.2 & 41.2 & 46.1 & 65.2 \\
& $\sigma$ & 30.4 & 30.8 & 31 & 22.4 & 32 & 28 & 25.6 & 28.3 & 24.3 & 29.5 & 28.5 & 25.2 \\
\multirow{2}{*}{ Lawyer } & $\mathrm{M}$ & 46.9 & 42 & 35.7 & 28.1 & 46.2 & 77.2 & 75.9 & 61.8 & 68.2 & 57.4 & 37.4 & 57.6 \\
& $\sigma$ & 27.1 & 27.2 & 32.7 & 32.3 & 31.1 & 21.5 & 18 & 25.4 & 33 & 29.9 & 24 & 29.9 \\
\hline
\end{tabular}

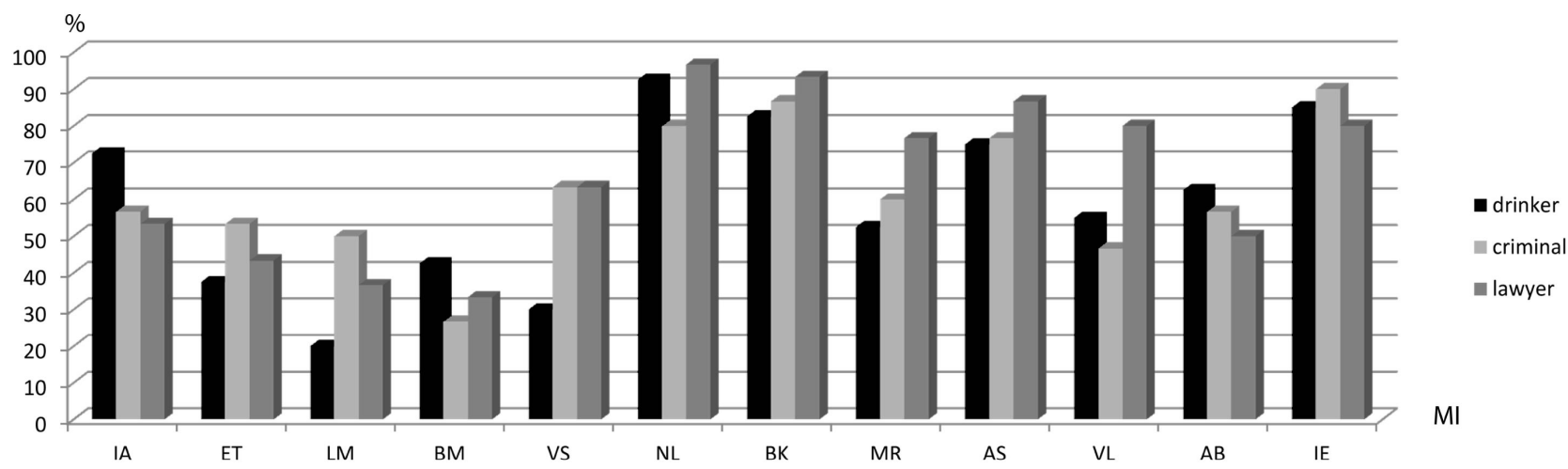

Figure 3. Multiple intelligences (MI) profile: conscious response (in the mode of Yes/No answers). 
In the group of young people abusing alcohol, the leading MI types appeared to be NL-Naturalistic (92.5\%), IE-Interpersonal (85\%) and BK-BodilyKinesthetic (82.5\%). In the young people who committed systematic theft the leading MI types appeared to be IE-Interpersonal (90\%), BK-Bodily-Kinesthetic (86.6\%), NL-Naturalistic (80\%). The leading MI types in the control group became NL-Naturalistic (96.6\%), BK-Bodily-Kinesthetic (93.3\%) and AS-Ascetic-Sacrificial (86.6\%).

In the groups of alcoholics and thieves (as distinct from the control group) the ratio of conscious response and the general MI profile is broken: there are distinctions on the degree of expressiveness and distinction in the ratio of leading MI types. Modern society in developed countries actively promotes careful attitude to nature (NL), interest in sports (BK), high sociability (IE) and the ideas of patronage (AS). The situation arises when social values are perceived as private, and a kind of self-deception occurs.

The analysis of the differences between the groups revealed the maximal discrepancies (in the form of a difference) of logical-mathematical (LM), visual-spatial (VS) and verbal-linguistic (VL) MI types. The persons prone to alcohol addiction estimate their mathematical abilities extremely low in comparison with law students $(\Delta 16.6 \%)$ and the persons who committed theft $(\Delta 30 \%)$. Because of the specific character of the addiction, young people addicted to alcohol modestly estimate their visual-spatial abilities in comparison with law students and the persons who committed theft $(\Delta 33.3 \%)$. The group of law students most highly estimated their own oratory and verbal-linguistic abilities as compared to the young people who committed theft $(\Delta 34.4 \%)$ and those abusing alcohol $(\Delta$ $25 \%)$.

Compare the results obtained with the data of unconscious attitudes shown in Figure 4.

The resulting MI profile illustrates unconscious attitudes of the examinees concerning their abilities, i.e. minimally reflects the social stereotypes of desirable behavior.

In the group of young people abusing alcohol, the leading MI types appeared

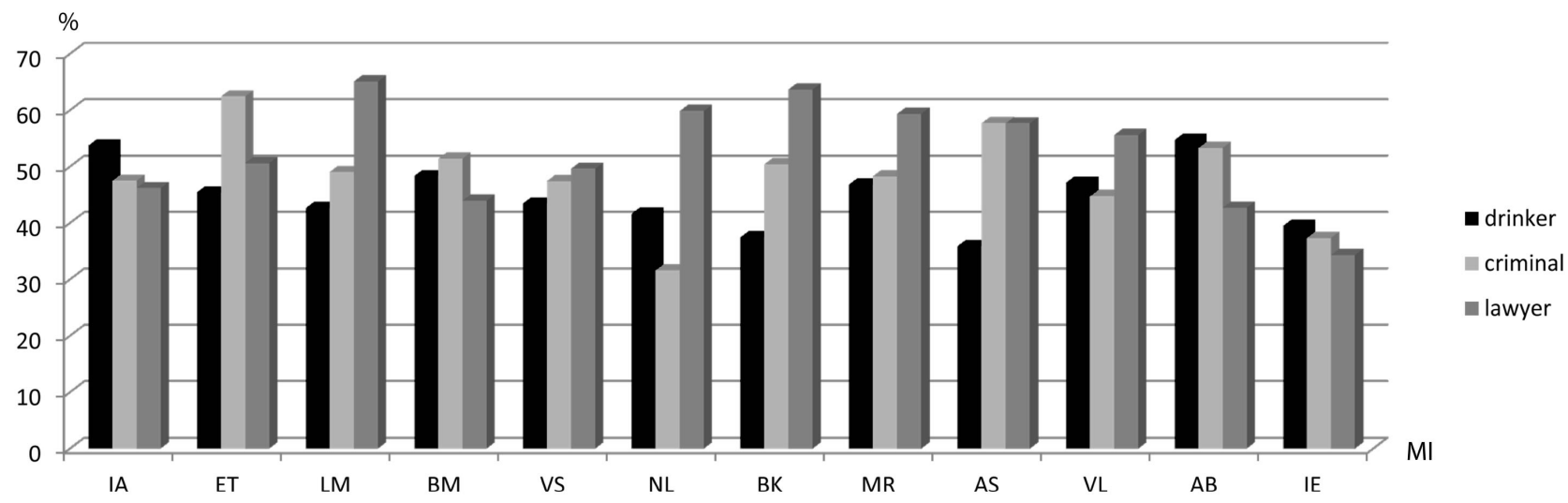

Figure 4. Multiple intelligences profile: unconscious response. 
to be: AB-Arts-Bohemian (54.7\%), IA-Intrapersonal (53.7\%) and BM-Business-Mercenary (48.3\%). The results obtained contrast with the general MI profile and the profile of conscious attitudes in the MI structure. We would like to note that such distribution of responses between conscious and unconscious responses in the mode of classical lie detection (via use of a polygraph or the $\mathrm{Vi}$ braLie program [36] [37]) should be considered as a manifestation of a lie. But, since it is about abilities, not about the events that really took place, we consider the results obtained as the manifestation of dissociation between conscious and unconscious attitudes of a disharmonious personality (an analog of limited abilities for professional self-fulfillment).

In the young people who committed systematic theft, the leading MI types MI appeared to be ET-Existential-Theoretical (62.4\%), AS-Ascetic-Sacrificial (57.6\%) and $\mathrm{AB}$-Arts-Bohemian (53.3\%) which contradicts the general MI profile and the profile of conscious attitudes in the MI structure.

In the control group, the leading MI types became: BK-Bodily-Kinesthetic (93.3\%), LM-Logical-Mathematical (65.07\%) and NL-Naturalistic (96.6\%). Two of the three leading MI types coincided with the general MI profile and the profile of conscious attitudes (as distinct from the experimental groups).

The maximal distinctions between the groups of examinees were concerning such MI types as: logical-mathematical (LM), naturalistic (NL) and bodily-kinesthetic (BK). At the unconscious level the group of law students estimates their mathematical abilities more highly than the young people with alcohol addiction $(\Delta 22.4 \%)$ and the young people who committed theft $(\Delta 16 \%)$.

\subsection{Analysis of the Difference between Conscious and Unconscious Components of the MI Profile}

The understanding of physical, chemical, biological and physiological laws allows converting and normalizing quantitative data, which characterize conscious responses and psychophysiological response of an examinee to a differential profile of multiple intelligences. Figure 5 shows the data on the difference (the differential MI profile) between conscious and unconscious responses, obtained when constructing MI profiles.

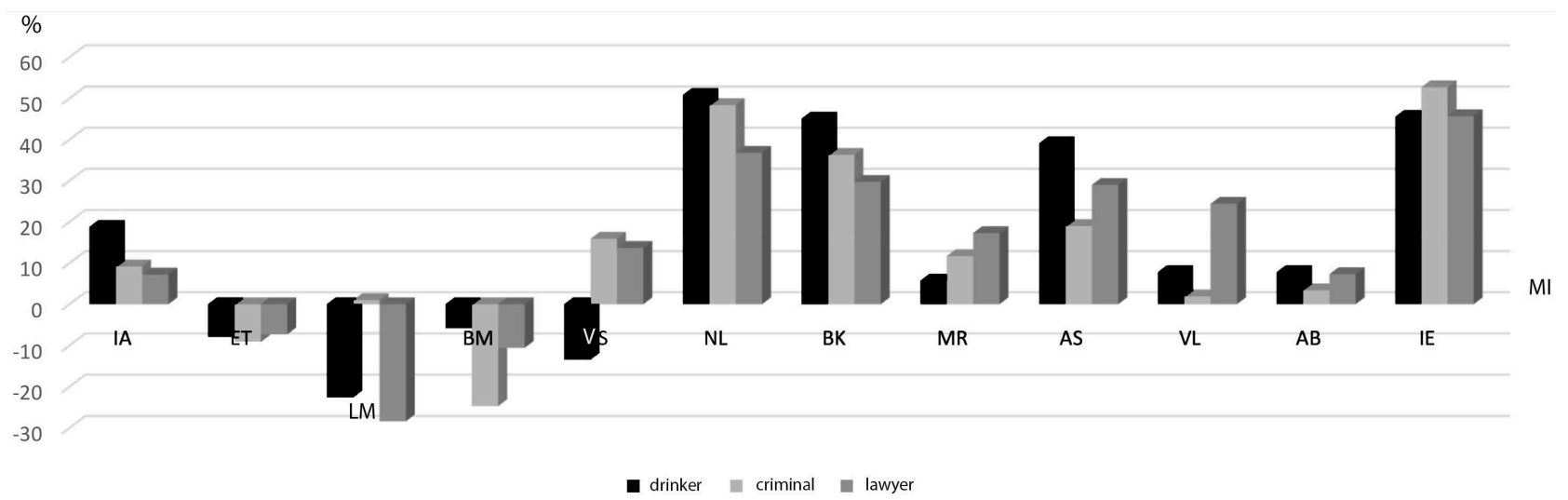

Figure 5. Differential profile of multiple intelligences: The difference between conscious and unconscious responses. 
From the differential profile of the examinees (Figure 5) it follows that in all the groups there is a considerable commonality of the tendencies in the distribution of MI types. Remarkably, the location is not symmetrical: positive values (the total number of differential MI types above the axis is equal to 9) outnumber negative values (the total number of differential MI types of the below the axis is equal to 3) by the number of MI types, i.e. conscious perceptions of one's own abilities have a greater weight (value) than unconscious perceptions for the groups under study. This ratio has slightly less expressed character in the group of young people with alcohol addiction, in favor of the negative values (4). Based on the results obtained, it can be assumed that social stereotypes are strong enough in the formation of self-assessment of intellectual abilities compared to the unconscious aspirations for the studied young people. Unconscious, intuitive type of aspirations may hide the available inclinations, a biological component of undeveloped abilities. Undeveloped inclinations, owing to any external reasons, can be sublimated in the most unexpected aspects of self-esteem and behavior.

Along with groupwide tendencies there were also obtained the individual differences reflecting a specific orientation of separate social groups. For example, in the group of young people who committed systematic theft, a real perception about their mathematical abilities coincide with unconscious attitudes, which is reflected in the so-called "comfort zone" $(\mathrm{LM}=1)$. By the "comfort zone" we mean the minimum dispersion of values of the analyzed index lower than $\pm 10 \%$. At the same time, law students $(-28.4 \%)$ and the young people with alcohol addiction $(-22.6 \%)$ at the unconscious level have more expressed aspirations concerning mathematical abilities than at the conscious level.

Similar tendency in these groups can be traced concerning business-mercenary (BM) type of MI. The young people who committed theft have more expressed commercial aspirations $(\mathrm{BM},-24.7 \%)$ at the unconscious level than in the control group $(\mathrm{BM},-10.6 \%)$, and in the group of young people who abuse alcohol (BM-5.8\%). At the same time the abilities to mathematics and business can be also criminal focused: thefts, trafficking and sale of stolen goods. As well as the perceptions of visual-spatial abilities (VS) in the young people with alcohol addiction, at the conscious level contrast with unconscious attitudes (the same cannot be observed in the other two groups). It is considered that in people with alcohol addiction spatial orientation is impaired (VS), which, however, is not confirmed at the level of psychophysiological response.

An ideal differential MI profile for the perfect person, from the viewpoint of equality of conscious and unconscious person's responses, should represent small columns of the MI types, which are not going beyond $\pm 10 \%$. In a harmoniously developed person, the area of the integral, which is higher and lower of the axis on the differential profile, should be approximately equal. In this case, a conscious response is prevailing for some MI types, and for other MI types-an unconscious response. At the same time, at large an approximate equality is observed. Figure 5 represents shows the results indicating that the values of differential MI profiles, obtained in the groups, are far from perfect and harmonious. 
Summing up the overall findings, one may say that the relationship between the profile of multiple intelligences, professional preferences and the orientation of social activity exists. The general trends, typical for the representatives of the same age group, being the residents of the same region (Saint-Petersburg, Russia), and specific issues characterizing certain social group have been revealed. Group wide tendencies shaped up as the asymmetric arrangement of MI types on the differential profile. Specific distinctions concern certain aspects of conscious and unconscious attitudes towards logical-mathematical (LM), business-mercenary (BM) and visual-spatial (VS) types of MI. Accordingly, different directions of social activity are reflected not only in the general profile of multiple intelligences, but also in its structural components.

\section{Discussion and Conclusion}

Abilities diagnostics, the need for specification of professional choice are observed during all professionally active human life [38] [39] [40] [41]. The standards of professional success required from career people, as a rule, are not limited to particular area, and are interdisciplinary, involving diverse fields of professional fulfillment. The specification of the professional choice is both personal and sociocultural need dictated by the changing standards of modern society. Therefore the monitoring of abilities and professional identity involves searching of such a model of intelligences that would satisfy these needs. In our opinion, Gardner's model structured and expanded to $12 \mathrm{MI}$ types is optimal. An important factor which caused the choice of this model of intelligences is the possibility of its implementation in different age and social groups where social activity and general trends of behavior (along with traditional characteristics of intelligence) are the markers of available abilities. The possibility of studying individual psychophysiological parameters for each type of MI makes the vibraimage technology attractive for a number of experts.

The conducted research in the specified groups of examinees showed ample opportunities of the method to identify hidden trends peculiar to certain social groups. If we assume that the revealed picture of differences between conscious and unconscious responses accurately reflects the hidden information, then this method can be the basis for identifying individuals who intend to commit criminal acts or who are predisposed to commit such acts. Changing the questions and stimuli, it is possible to carry out similar profiling and obtain an examinee profile not only on multiple intelligences but also on any of the investigated areas, for example, relation to terrorism, loyalty to democratic or monarchic values, commitment to a particular religion, etc.

The question of estimation accuracy of psychophysiological parameters of an individual, certainly, demands a larger set of statistics, and it was not investigated in this paper. Although in the previous work [29] there was given the assessment of the value of error, when determining the integral values of MI types, which did not exceed $10 \%$ in the conducted experiments. At the same time, the 
differential assessment reflecting the hidden information must have a greater accuracy and lower errors [37] than the integrated assessment of values of MI types. However, the stability of the differential assessment largely depends on the stability of the relationship between the conscious and unconscious responses of person, the study of the relationship of the conscious to the unconscious is the subject of a separate research.

\section{Limitations}

The use of vibraimage technology for conducting research has many limitations, directly related to the technology requirements defined by the quality of the obtained images [30]. These are primarily the stability of illumination intensity of an object under study, the absence of mechanical vibrations of the used television camera, and low level of hardware noise of the resulting videos. To confirm or refute the obtained results, it is reasonable to conduct a mass of experiments by the proposed technique, since a limited number of examinees participating in an experiment leaves room for different opinions and discussions.

\section{Social Implications}

The authors hope that the use of this technology will become a source of ergonomic distribution of energy resources in the process of professional identity and the correction of the route of social activity of a person at all stages of life (at school, College, University, retraining, interview).

\section{Future Research}

The use of the obtained results and the application of the vibraimage technology will allow measuring the current information-energy psychophysiological state of a person, and, along with traditional psychological tests, carrying out statistical processing of the obtained data similarly to the traditional measurements of physical values, which is necessary for many applications. The given researches confirm the feasibility of MI as the most complete characteristics of a personality, when conducting various tests, allowing measuring the changes of psychophysiological state more accurately than traditional techniques of obtaining time-dependency of physiological parameters. The developed approach of the analysis of differential MI profile on the basis of the difference between conscious and unconscious response to a stimulus makes it possible to implement testing of examinees on various subjects, including those which are not associated with MI.

The use of the vibraimage technology, MI and the described technique of testing will allow solving such applied problems as defining abilities in children, occupational guidance for senior schoolchildren, vocational counseling and personnel management, assistance with professional retraining. VibraMI can be useful to the experts working in the sphere of applied psychology (general and clinical), for profiling and recruiting. 
The combination of psychological and psychophysiological methods in one technique of human study opens novel opportunities to obtain the information about human personality concerning aberrations, including deviant behavior. Statistical processing of personal testing results allows identifying an individual against a particular social group.

\section{Acknowledgements}

This work was supported by the Research Program of Elsys Corp. 2017. Thanks to Mrs. Galina Filimonova for the quality translation of difficult Russian text.

\section{References}

[1] Gardner, H. (1983) Frames of Mind: The Theory of Multiple Intelligences. New York.

[2] Gardner, H. (1993) Multiple Intelligences: The Theory in Practice. Basic Book, New York.

[3] Sechenov, I. (1965) Reflexes of the Brain. The MIT Press, 230 p.

[4] Darwin, C. (1872) The Expression of the Emotions in Man and Animals. John Murray, London. https://doi.org/10.1037/10001-000

[5] Freud, S. (2010) The Interpretation of Dreams. Basic Books, 688 p.

[6] Pavlov, I.P. (1927) Conditioned Reflexes: An Investigation of the Physiological Activity of the Cerebral Cortex. Translated and Edited by G. V. Anrep. Oxford University Press, London, 142.

[7] Bernstein, N.A. (1967) The Co-Ordination and Regulation of Movements. Pergamon Press, Oxford.

[8] Lorenz, K. (1966) On Aggression. (Das sogenannte Böse. Zur Naturgeschichte der Aggression, 1963). Original Edition: Verlag Dr. G Borotha-Schoeler.

[9] Mira y López, E. (1958) Myokinetic Psychodiagnosis. Logos Press, New York.

[10] Minkin, V. (2017) Vibraimage. Renome, Saint-Petersburg, 108 p.

[11] Spearman, C.E. (1904) General Intelligence, Objectively Determined and Measured. American Journal of Psychology, 15, 201-292.

[12] Sternberg, R.J. (1975) Review of D. Stenhouse, the Evolution of Intelligence. American Scientist, No. 63, 476 p.

[13] Stein, S.J. and Book, H.E. (2000) The EQ Edge: Emotional Intelligence and Your Success. Stoddart, Toronto.

[14] Gardner, H. (2011) The Theory of Multiple Intelligences: As Psychology, as Education, as Social Science. Address Delivered at José Cela University on October 29, Madrid.

[15] Myers, D.G. and Twenge, J.M. (2016) Social Psychology. 12th Edition, McGraw-Hill, New York.

[16] Myers, D.G. (2015) Exploring Social Psychology. 7th Edition, McGraw-Hill Education, New York.

[17] Lombroso, C. (1859) Ricerchesulcretinismo in Lombardia. Gazz. Medico, Italiana, No. 13.

[18] ISO/IEC 2382-37:2012 Information Technology-Vocabulary-Part 37: Biometrics.

[19] Dary, I.J., Penke, L. and Johnson, W. (2010) The Neuroscience of Human Intelli- 
gence Differences. Nature Reviews Neuroscience, 11, 201-211.

https://doi.org/10.1038/nrn2793

[20] Carroll, J.B. (1993) Human Cognitive Abilities: A Survey of Factor Analytic Studies. Cambridge University Press, Cambridge. https://doi.org/10.1017/CBO9780511571312

[21] Minkin, et al. (2008) US 7346227 Method and Device for Image Transformation. Date of Patent Mar. 18.

[22] Minkin, V. (2017) RU 2017109920 Method of Psychophysiological State Assessment.

[23] Minkin, V.A. and Nikolaenko, N.N. (2008) Application of Vibraimage Technology and System for Analysis of Motor Activity and Study of Functional State of the Human Body. Biomedical Engineering, 42, 196-200.

https://doi.org/10.1007/s10527-008-9045-9

[24] Hwang, S.T., Park, S., Won, M., Choi, K. and Whang, M. (2014) Evaluation of Social Relationship between Two Persons using Micro-Movement in Vestibular System. Vol. 5, 535-539.

[25] Park, J., Choi, K. and Hwang, S. (2014) A Study on Emotional Classification Algorithm using Vibraimage Technology. Vol. 5, 664-667.

[26] Wiener, N. (1961) Cybernetics: Or Control and Communication in the Animal and the Machine. 2nd Revised Edition, MIT Press, Paris.

[27] Shannon, C.E. (1948) A Mathematical Theory of Communication. Bell System Technical Journal, 27, 379-423, 623-656.

[28] Halberg, F. (1987) Perspectives of Chronobiologic Engineering. Volume 120 of the Series NATO ASI Series, 1-46.

[29] Deary, I.J., Whalley, L.J., Lemmon, H., Crawford, J.R. and Starr, J.M. (2000) The Stability of Individual Differences in Mental Ability from Childhood to Old Age: Follow-Up of the 1932 Scottish Mental Survey. Intelligence, 28, 49-55.

[30] Minkin, V.A. and Nikolaenko, Y.N. (2017) Vibraimage and Multiple Intelligences. Saint-Petersburg, Renome, 156 p. (In Russian)

[31] Elsys Corp. (2017) Psychophysiological Profiling System, Manual, Version VibraMI 10. http://psymaker.com/downloads/VibraMIEng10.pdf

[32] Elsys Corp. (2017) VibraStatMI. Statistical Processing of VibraMI10 Program Results. http://psymaker.com/downloads/VibraStatMI.pdf

[33] LibbThims (2007) Human Chemistry. LuLu Enterprises, 370.

[34] Skinner, B.F. (1931) The Concept of the Reflex in the Description of Behavior. Journal of General Psychology, 5, 427-458.

[35] National Academies of Sciences, Engineering, and Medicine (2016) 2015-2016, Assessment of the Army Research Laboratory: Interim Report. The National Academies Press, Washington DC.

[36] Elsys Corp. (2017) VibraLie 10, Psychophysiological Contactless Lie Detection System. http://www.psymaker.com/downloads/VibraLieEng10.pdf

[37] Leon Brillouin (1962) Science and Information Theory. Academic Press, 363 p.

[38] Baur, D.J. (2006) Federal Psychophysiological Detection of Deception Examiner Handbook, Counterintelligence Field Activity Technical Manual.

[39] Deary, I.J. (2007) Looking Down on Human Intelligence: From Psychometrics to the Brain. Oxford University Press, Oxford.

[40] Deary, I.J., Strand, S., Smith, P. and Fernandes, C. (2007) Intelligence and Educa- 
tional Achievement. Intelligence, 35, 13-21.

[41] Strenze, T. (2007) Intelligence and Socioeconomic Success: A Meta-Analytic Review of Longitudinal Research. Intelligence, 35, 401-426. 